\title{
Esophageal Motility in the Supine and Upright Positions for Liquid and Solid Swallows Through High-resolution Manometry
}

\author{
Xiujing Zhang, Xuelian Xiang, Lei Tu, Xiaoping Xie and Xiaohua Hou* \\ Division of Gastroenterology, Union Hospital of Tongji Medical College, Huazhong University of Science and Technology, Wuhan, China
}

\begin{abstract}
Background/Aims
Most recent studies using high-resolution manometry were based on supine liquid swallows. This study was to evaluate the differences in esophageal motility for liquid and solid swallows in the upright and supine positions, and to determine the percentages of motility abnormalities in different states.
\end{abstract}

\begin{abstract}
Methods
Twenty-four asymptomatic volunteers and 26 patients with gastroesophageal reflux disease underwent high-resolution manometry using a 36-channel manometry catheter. The peristalses of 10 water and 10 steamed bread swallows were recorded in both supine and upright positions. Integrated relaxation pressure, contractile front velocity, distal latency (DL) and the distal contractile integral (DCl) were investigated and comparisons between postures and boluses were analyzed. Abnormal peristalsis of patients was assessed applying the corresponding normative values.
\end{abstract}

\section{Results}

In total, 829 swallows from healthy volunteers and 959 swallows from patients were included. (1) The upright position provided lower integrated relaxation pressure, shorter DL and weaker DCl than the supine position. (2) In the comparison of liquid swallows, the mean for contractile front velocity was obviously reduced while DL and DCI were increased in solid swallows. (3) The supine position detected more hypotensive peristalsis than the upright position. The upright position provided more rapid and premature contraction than the supine position but there was no statistically significant difference.

\section{Conclusions}

Supine solid swallows occur with more hypotensive peristalsis. Analysis should be based on normative values from the corresponding posture and bolus.

\section{(J Neurogastroenterol Motil 2013;19:467-472)}

Key Words

Esophageal motility disorders; High-resolution manometry; Posture

Received: April 1, 2013 Revised: July 1, 2013 Accepted: July 15, 2013

(c) This is an Open Access article distributed under the terms of the Creative Commons Attribution Non-Commercial License (http://creativecommons. org/licenses/by-nc/3.0) which permits unrestricted non-commercial use, distribution, and reproduction in any medium, provided the original work is properly cited.

*Correspondence: Xiaohua Hou, MD

Division of Gastroenterology, Union Hospital of Tongji Medical College, Huazhong University of Science and Technology, 1277 Jiefang Road, Wuhan 430022, China

Tel: +86-027-85726057, Fax: +86-027-85726057, E-mail: houxh@medmail.com.cn

Financial support: The study was supported by the foundation of the Key clinical project of the Ministry of Health in China (2010439). The English Conflicts of interest: None. was edited by International Science Editing.

Author contributions: Xiujing Zhang was involved in data analysis, results statistics and writing the manuscript. Xuelian Xiang \& Lei Tu were involved in study concept, acquisition of data and providing some comments on the content. Xiaoping Xie was involved in administrative and technical support. Xiaohua Hou was involved in research designing, study supervision and critical revision of the manuscript. 


\section{Introduction}

High-resolution esophageal pressure topography was described by Clouse and Staiano for clinical practice since the 1990s. ${ }^{1}$ The evolution of technology combined high-resolution manometry (HRM) and pressure topography plotting. High-resolution esophageal manometry is more sensitive to esophageal dysmotility that causes symptoms. ${ }^{2-5}$ It increases the accuracy of predicting bolus transport and facilitates the analysis of esophageal motility. $^{2-4}$

The current diagnostic criterion for an esophageal pressure topography result is based on the Chicago classification, which is predicated on 10 repeated $5 \mathrm{~mL}$ water-swallows in the supine position. ${ }^{6-9}$ But generally speaking, swallowing occurs in the upright position with the liquid and solid substances. In the supine position, some patients may not be able to tolerate the manometry such as those with achalasia. Clinical symptoms are triggered easier by solid than by small volumes of water. So it may be more reasonable to evaluate esophageal peristalsis during the solid swallowing and in the upright position.

Some investigations reported that esophageal peristalsis was altered with body posture and type of bolus. ${ }^{10-14}$ Many authors have pointed out that the percentages of normal waves were lower in the sitting position with solid swallows, ${ }^{12,13,15}$ and the distal esophageal contractile response showed an increased number of failed swallows and simultaneous contractions for solids compared to liquids, especially in the upright position. ${ }^{13}$ A study by Bernhard et $\mathrm{al}^{16}$ showed there was a significant difference between the proportions of patients with normal manometry during recumbent water swallows (74\%), upright water swallows (60\%), recumbent bread swallows $(58 \%)$ and upright bread swallows (49\%). The percentages of patients with ineffective esophageal motility were greater in the upright and bread swallows.

However, all of previous studies evaluated abnormal peristalsis applying the normative values with supine liquid swallows. This suggests that cutoffs for abnormality established in the supine position may not be valid in the sitting position.

The aim of this study was to establish normative values for liquid and solid swallows in the supine and upright positions. Then the percentages of esophageal motility abnormalities for patients in different postures and boluses were assessed based upon the normal values from healthy volunteers.

\section{Materials and Methods}

\section{Subjects}

Twenty-four asymptomatic volunteers (male 11:female 13, average $38.0 \pm 10.0$ years old, body mass index $22.3 \pm 5.2$ $\mathrm{Kg} / \mathrm{m}^{2}$ ) and 26 patients (male 12:female 24, average $44.8 \pm 8.7$ years old, body mass index $22.5 \pm 3.2 \mathrm{Kg} / \mathrm{m}^{2}$ ) were recruited by advertisement or word of mouth. An exclusion criterion was upper gastrointestinal surgery history. No medication affecting esophageal motility or antacids were used for at least 1 week. All subjects underwent upper gastrointestinal endoscopy to rule out peptic ulcers, malignant tumors and erosive gastritis. Informed consent was obtained prior to participation in the study. The asymptomatic volunteers were without any gastrointestinal symptoms for at least 6 months. Patients with gastroesophageal reflux disease (GERD) were included, as assessed by the self-administered GERD questionnaire (GerdQ score $\geq 8$ ). The study protocol was approved by the Ethics Committee of Tongji Medical College, Huazhong University of Science and Technology.

\section{Manometry Procedure}

Manometric data were obtained using a $4.2 \mathrm{~mm}$ outer diameter solid-state manometry catheter assembly with 36 circumferential sensors spaced at $1 \mathrm{~cm}$ intervals (Manoscan 360; Sierra Scientific Instruments Inc, Los Angeles, CA, USA). Studies were performed after a minimum of 8 hours fasting. The catheter was calibrated and zeroed to atmospheric pressure. It was inserted intranasally until at least three sensors were in the stomach and positioned by taping it to the nose to record the pressure from the hypopharynx to the stomach. All participants began with a supine (flat on the back $0-20^{\circ}$ ) or upright position (sitting in a chair $70-90^{\circ}$ ) randomly. After a 5 - to 10 -minute period of acclimatization and recording basal pressure for 30 seconds without swallowing, subjects underwent 10 water swallows $(5 \mathrm{~mL})$ and 10 steamed bread swallows $(2 \mathrm{~cm} \times 2 \mathrm{~cm} \times 2 \mathrm{~cm})$. They were instructed to swallow only once and not to swallow again until the next bolus. Each swallow was allowed at 20 to 30 seconds interval. Sequentially, subjects changed to the other posture and repeated the water and steamed bread swallows.

\section{Data Analysis}

Manometric data were initially analyzed using ManoView ${ }^{\text {TM }}$ analysis software 2.0.1 version (Sierra Scientific Instruments Inc). 
Then one person was scrutinized on a case-by-case basis and adjusted manually, if necessary, to ensure the accuracy of every parameter. A swallow with more than once deglutition or cough was rejected. The asymptomatic volunteers that had less than 70 percent intact swallows for any position and bolus were rejected.

The parameters of 4 seconds integrated relaxation pressure (IRP), contractile front velocity (CFV), distal latency (DL) and distal contractile integral (DCI) were measured. ${ }^{7}$ Comparisons were then made between different postures and boluses. A swallow was defined as a hypotensive contraction if the value of DCI was less than the normative value of the DCI. Rapid contraction was defined when the CFV of patients was over the upper limit of mean $\pm \mathrm{SD}$. When DL was lower than the lower limit mean \pm $\mathrm{SD}$, it was recorded as a premature contraction. Rapid and premature contractions were not evaluated for swallows with minimal ( $<3 \mathrm{~cm}$ ) integrity of the $20 \mathrm{mmHg}$ isobaric contour distal to the proximal pressure trough.

\section{Statistical Methods}

Results are reported as mean $\pm \mathrm{SE}(\mathrm{SD})$ and median (interquartile range $[\mathrm{IQR}])$. A Wilcoxon matched-pairs signed-ranks test and paired $t$ test were used for between group analysis (supine vs. upright and liquid vs. solid). Abnormal peristalsis was compared using a Chi-square test. $P<0.05$ was considered as statistically significant.

\section{Results}

Fifty subjects (24 asymptomatic volunteers and 26 patients) were recruited. Of the 24 asymptomatic volunteers, 2 were rejected because of less than 70 percent perfect swallows. One asymptomatic subject and 1 patient could not tolerate the manometry protocol and dropped out. Twenty-one healthy volunteers and 25 patients were included in the final analysis. A total of 829 swallows from healthy participants (210 supine liquid, 205 supine solid, 205 upright liquid and 209 upright solid) and 959 swallows of patients (249 supine liquid, 232 supine solid, 250 upright liquid and 228 upright solid) were included.

\section{Differences in Esophageal Peristalsis in the Supine and Upright Positions}

As evident in Table 1, in both liquid and solid swallows, com-

Table 1. Normal Values for the Parameters of Esophageal Motility From 21 Healthy Volunteers in Supine and Upright Positions for Liquid and Solid Swallows

\begin{tabular}{|c|c|c|c|c|c|c|c|}
\hline & \multicolumn{3}{|c|}{ Health-supine } & \multicolumn{3}{|c|}{ Health-upright } & \multirow[b]{2}{*}{$P$-value ${ }^{\mathrm{a}}$} \\
\hline & $\begin{array}{l}\text { Mean } \pm \mathrm{SE} \\
\quad(\mathrm{SD})\end{array}$ & $\begin{array}{c}\text { Median } \\
\text { (IQR) }\end{array}$ & 5th-95th & $\begin{array}{l}\text { Mean } \pm \mathrm{SE} \\
\quad(\mathrm{SD})\end{array}$ & $\begin{array}{c}\text { Median } \\
\text { (IQR) }\end{array}$ & 5th-95th & \\
\hline \multicolumn{8}{|l|}{ Liquid } \\
\hline IRP (mmHg) & $\begin{array}{c}7.6 \pm 0.2 \\
(2.6)\end{array}$ & $\begin{array}{c}7.3 \\
(5.9,8.7)\end{array}$ & $3.4-12.7$ & $\begin{array}{c}5.5 \pm 0.3 \\
(3.5)\end{array}$ & $\begin{array}{c}5.2 \\
(2.4,8.2)\end{array}$ & $0.2-11.6$ & 0.017 \\
\hline $\mathrm{CFV}(\mathrm{cm} / \mathrm{sec})$ & $\begin{array}{l}4.0 \pm 0.1 \\
(2.2)\end{array}$ & $\begin{array}{c}3.8 \\
(3.3,4.6)\end{array}$ & $2.5-6.7$ & $\begin{array}{l}4.6 \pm 0.3 \\
(2.1)\end{array}$ & $\begin{array}{c}3.9 \\
(3.2,5.3)\end{array}$ & $2.5-8.9$ & 0.140 \\
\hline $\mathrm{DL}(\mathrm{sec})$ & $\begin{array}{l}6.4 \pm 0.1 \\
(1.0)\end{array}$ & $\begin{array}{c}6.2 \\
(5.5,7.2)\end{array}$ & $4.5-9.0$ & $\begin{array}{l}5.9 \pm 0.1 \\
(1.3)\end{array}$ & $\begin{array}{c}5.9 \\
(5.0,6.7)\end{array}$ & $4.1-8.2$ & 0.023 \\
\hline $\begin{array}{l}\text { DCI } \\
\qquad(\mathrm{mmHg} / \mathrm{cm} \cdot \mathrm{sec})\end{array}$ & $\begin{array}{c}1,596.9 \pm 63.6 \\
(916.9)\end{array}$ & $\begin{array}{c}1,508.4 \\
(940.8,2,030.9)\end{array}$ & $293.4-3,320.0$ & $\begin{array}{c}1,259.0 \pm 72.1 \\
(996.8)\end{array}$ & $\begin{array}{c}811.3 \\
(386.9,1,923.7)\end{array}$ & $64.9-3,264.7$ & 0.008 \\
\hline \multicolumn{8}{|l|}{ Solid } \\
\hline IRP (mmHg) & $\begin{array}{c}7.3 \pm 0.3 \\
(4.1)\end{array}$ & $\begin{array}{c}6.5 \\
(4.5,10.0)\end{array}$ & $1.8-14.5$ & $\begin{array}{c}6.4 \pm 0.3 \\
(4.7)\end{array}$ & $\begin{array}{c}6.2 \\
(2.7,9.1)\end{array}$ & $0.3-12.9$ & 0.042 \\
\hline $\mathrm{CFV}(\mathrm{cm} / \mathrm{sec})$ & $\begin{array}{l}2.7 \pm 0.2 \\
(1.1)\end{array}$ & $\begin{array}{c}2.4 \\
(2.1,2.8)^{b}\end{array}$ & $1.5-5.0$ & $\begin{array}{l}2.8 \pm 0.1 \\
(1.0)\end{array}$ & $\begin{array}{c}2.6 \\
(2.2,3.2)^{\mathrm{b}}\end{array}$ & $1.8-4.8$ & 0.187 \\
\hline $\mathrm{DL}(\mathrm{sec})$ & $\begin{array}{l}10.0 \pm 0.2 \\
\quad(2.7)\end{array}$ & $\begin{array}{c}9.9 \\
(8.6,11.6)^{\mathrm{b}}\end{array}$ & $5.8-14.7$ & $\begin{array}{l}9.0 \pm 0.1 \\
(2.0)\end{array}$ & $\begin{array}{c}9.0 \\
(7.6,10.6)^{\mathrm{b}}\end{array}$ & $5.7-12.5$ & 0.000 \\
\hline $\begin{array}{l}\text { DCI } \\
\qquad(\mathrm{mmHg} / \mathrm{cm} \cdot \mathrm{sec})\end{array}$ & $\begin{array}{c}2,941.2 \pm 101.2 \\
(1,403.0)\end{array}$ & $\begin{array}{c}2,764.2 \\
(1,896.3,3,726.8)^{b}\end{array}$ & $576.9-5,672.4$ & $\begin{array}{c}2,100.7 \pm 91.6 \\
(1,305.2)\end{array}$ & $\begin{array}{c}1,688.5 \\
(1,086.7,2,804.2)^{b}\end{array}$ & $340.6-4,932.0$ & 0.000 \\
\hline
\end{tabular}

${ }^{\mathrm{a}} P$-value presented the comparison between upright and supine position with paired $t$ test; ${ }^{\mathrm{b}}$ With statistical difference $(P<0.05)$ compared between liquid and solid of the corresponding posture with paired $t$ test.

IQR, interquartile range; IRP, integrated relaxation pressure; CFV, contractile front velocity; DL, distal latency; DCI, distal contractile integral. 
Table 2. Values of the Parameters for Esophageal Motility From 25 Patients in Supine and Upright Positions for Liquid and Solid Swallows

\begin{tabular}{|c|c|c|c|c|c|}
\hline & \multicolumn{2}{|c|}{ Patient-supine } & \multicolumn{2}{|c|}{ Patient-upright } & \multirow{2}{*}{$P$-value } \\
\hline & Mean $\pm \mathrm{SE}(\mathrm{SD})$ & Median (IQR) & Mean $\pm \mathrm{SE}(\mathrm{SD})$ & Median (IQR) & \\
\hline \multicolumn{6}{|l|}{ Water } \\
\hline IRP (mmHg) & $8.0 \pm 0.3(4.2)$ & $7.7(4.9,10.2)$ & $5.3 \pm 0.3(4.0)$ & $4.8(2.2,7.4)$ & 0.004 \\
\hline $\mathrm{CFV}(\mathrm{cm} / \mathrm{sec})$ & $4.8 \pm 0.1(1.6)$ & $4.3(3.4,5.2)$ & $5.4 \pm 0.3(3.8)$ & $4.3(3.4,5.4)$ & 0.287 \\
\hline $\mathrm{DL}(\mathrm{sec})$ & $6.4 \pm 0.1(1.6)$ & $6.3(5.8,6.8)$ & $6.0 \pm 0.1(1.6)$ & $5.9(4.9,6.8)$ & 0.059 \\
\hline $\begin{array}{l}\text { DCI } \\
\qquad(\mathrm{mmHg} / \mathrm{cm} \cdot \mathrm{sec})\end{array}$ & $1,175.2 \pm 68.4(974.4)$ & $906.7(464.1,1,609.4)$ & $1,014.5 \pm 76.0(1,055.5)$ & $630.8(237.8,1,279.4)$ & 0.029 \\
\hline \multicolumn{6}{|l|}{ Solid } \\
\hline IRP (mmHg) & $8.4 \pm 0.3(3.9)$ & $8.0(5.6,10.5)$ & $5.3 \pm 0.3(4.0)$ & $5.1(2.9,8.4)$ & 0.004 \\
\hline $\mathrm{CFV}(\mathrm{cm} / \mathrm{sec})$ & $3.2 \pm 0.2(3.2)$ & $2.8(2.4,3.2)^{\mathrm{b}}$ & $3.6 \pm 0.3(3.8)$ & $2.8(2.5,3.3)^{\mathrm{b}}$ & 0.458 \\
\hline $\mathrm{DL}(\mathrm{sec})$ & $9.3 \pm 0.2(2.9)$ & $8.9(8.1,10.0)^{b}$ & $8.5 \pm 0.1(1.8)$ & $8.3(7.5,9.5)^{b}$ & 0.068 \\
\hline $\begin{array}{l}\mathrm{DCI} \\
(\mathrm{mmHg} / \mathrm{cm} \cdot \mathrm{sec})\end{array}$ & $2,021.5 \pm 110.3(1,543.7)$ & $1,554.1(813.1,3,010.8)^{\mathrm{b}}$ & $1,447.3 \pm 96.3(1,376.0)$ & $888.5(469.0,2,111.2)^{\mathrm{b}}$ & 0.001 \\
\hline
\end{tabular}

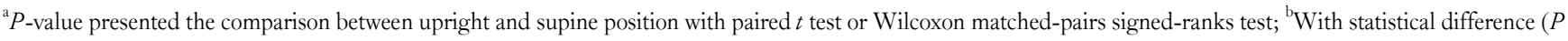
$<0.05$ ) compared between liquid and solid of the corresponding postures.

IQR, interquartile range; IRP, integrated relaxation pressure; CFV, contractile front velocity; DL, distal latency; DCI, distal contractile integral.

pared to the supine position, the IRP, DCI and DL of healthy volunteers were all significantly reduced in the upright position, while CFV was increased slightly (liquid $P=0.140$ and solid $P$ $=0.281$ ).

The data for esophageal motility from patients are shown in Table 2. The results were similar to those from healthy subjects. Significantly decreased IRP and DCI could be seen in the upright position of patients. $\mathrm{CFV}$ was a little faster (liquid $P=$ 0.287 and solid $P=0.458$ ) while DL was a little shorter in the upright position (liquid $P=0.059$ and solid $P=0.068$ ).

\section{Difference in Esophageal Peristalsis for Liquid and Solid Boluses}

For solid swallows, DL and DCI were increased with statistical significance compared to liquid swallows (DL, both $P=$ 0.000 and DCI, both $P=0.000)$ in any position. CFV was obviously decreased for solid swallows (supine $P=0.005$ and upright $P=0.000)$. The difference in IRP was not statistically significantly different for liquid $(P=0.785)$ and solid swallows $(P$ $=0.068)$ (Table 1$)$.

The solid swallows of patients had a slower CFV (supine $P=$ 0.006 and upright $P=0.001$ ), longer DL (both supine and upright $P=0.000$ ) and stronger DCI (both $P=0.000$ ). IRP was similar between solid $(P=0.425)$ and liquid $(P=0.384)$ swallows (Table 2).

\section{Esophageal Dysmotility in Different Positions and Boluses}

In the comparison with healthy controls, only DCI was decreased significantly in patients (supine liquid $P=0.028$, supine solid $P=0.007$, upright liquid $P=0.047$ and upright solid $P=$ 0.030) (Fig. 1).

There were $111(44.6 \%)$ hypotensive contractions in the supine liquid swallows, $100(40.0 \%)$ in the upright liquid swallows, 125 (53.9\%) in the supine solid swallows and 107 (46.9\%) in the upright solid swallows. There were more hypotensive contractions in the state of supine solid swallows than supine liquid swallows ( $P=0.041)$ (Fig. 2).

No obvious difference was observed for swallows with abnormal IRPs between different boluses and positions (22 supine liquid, 19 upright liquid, 20 supine solid and 10 supine liquid).

In the 959 swallows of patients, 796 swallows (203 supine liquid, 196 supine solid, 193 upright liquid and 204 upright solid) were analyzed for rapid contraction and premature contraction. The percentages of rapid and premature contractions were not significantly different in any position or type of bolus (all $P>$ 0.05 ) (Fig. 2).

\section{Discussion}

Deglutition occurs almost exclusively in the upright position. It seems more reasonable to evaluate esophageal symptoms in the 


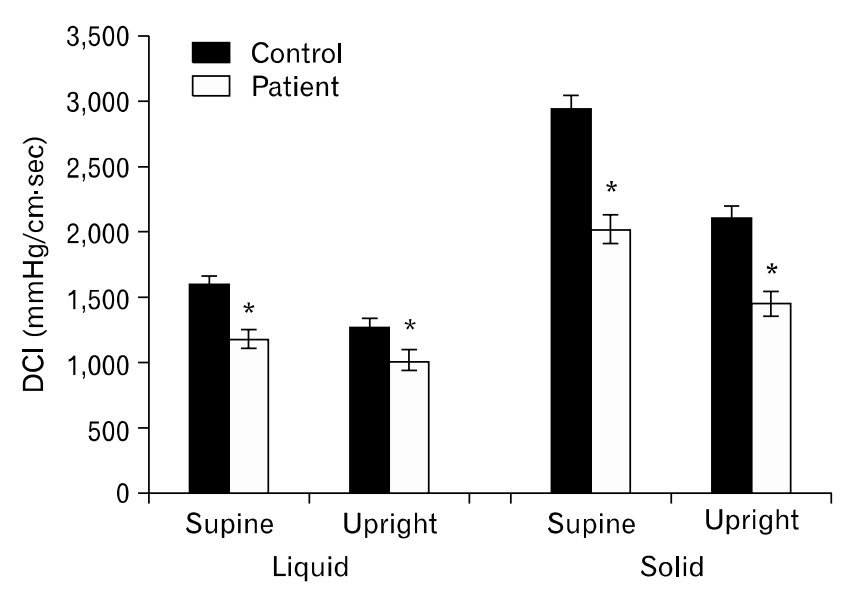

Figure 1. The values (mean and SE) of distal contractile integral from the controls and patients in supine and upright positions for liquid and solid swallows. All * $P<0.05$ indicate statistical difference between healthy volunteers and patients. DCI, distal contractile integral.

more physiologic upright position, ${ }^{16}$ especially in patients with severe impairment of bolus transport. Solid bolus may trigger dysmotility more easily than small volumes of water. ${ }^{13}$ This study investigated the influence of posture and bolus consistency on esophageal motility in the supine and upright positions for liquid and solid swallows using a solid HRM system and also assessed the percentages of esophageal motility abnormalities for patients in different postures and boluses based on the corresponding normative values from healthy volunteers.

The major findings were that: (1) the IRP, DL and DCI were significantly lower in the upright position than in the supine position; (2) slower CFV, longer DL and stronger DCI were seen for the solid compared to liquid swallows; (3) patients with GERD had weaker esophageal body pressure than healthy volunteers; and (4) more hypotensive cases were seen in the supine solid swallows, while rapid and premature contractions showed no statistical difference for different postures and boluses.

While the workload was increased in the supine position and solid swallowing, esophageal contractile responses were slower (lower CFV and longer DL) and more vigorous (greater DCI). Also, there was a decrease in IRP in the upright compared to the supine position. The changes in esophageal motility metrics with different positions and boluses were consistent with previous studies. ${ }^{11,12,14}$ In our study, IRP was slightly influenced by bolus consistency while the effect of posture on CFV was not significant. Xiao et $\mathrm{al}^{14}$ reported $\mathrm{CFV}$ was much faster in the supine position than in the upright position. The reason for this may be related to differences in demographic factors between the pop-

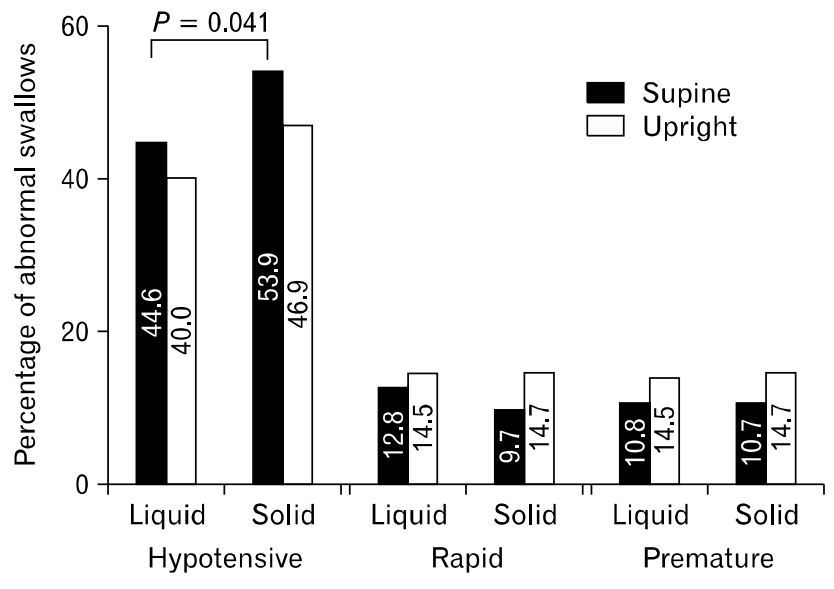

Figure 2. Percentage of hypotensive, rapid and premature contractions in the supine and upright positions for liquid and solid swallows.

ulations studied such as age, obesity, racial background and details of the swallowing protocol. ${ }^{14,17-19}$

In the comparison of positions, an increased frequency of hypotensive peristalsis was seen in the supine position. More rapid and premature contractions were present in the upright position since bolus transport depends on esophageal function completely in the supine position. Without the help of gravity, more failed swallows and very hypotensive peristalses were seen in the supine position and bolus transporting was faster in the upright position. Most previous studies demonstrated that atypical wave forms (defined as non-transmitted, simultaneous and simultaneous/repetitive) were increased in the upright position compared to the supine position. ${ }^{11,12,20}$ Another study reviewed 96 patients for dysphagia, chest pain and GERD symptoms, which found that differences between the percentages of normal, ineffective and simultaneous swallows were not statistically significant in supine and upright positions for liquids and solids in all patients. ${ }^{16}$ These differences may have derived from using supine normal values to interpret upright or sitting manometric studies in previous studies. This resulted in excess peristaltic dysfunction in the upright position. This issue also may be related to demographic differences. $^{13}$

Previous data revealed a solid or viscous bolus produced more hypotensive contractions than liquids. ${ }^{11-13,21}$ Basseri et $\mathrm{al}^{22}$ published a study on 41 dysphagia patients comparing esophageal contractions elicited by viscous and liquid boluses. They found that a viscous bolus produced more hypotensive and simultaneous contractions. In our study, solid swallows had more hypotensive contractions than liquid swallows. There was a statistically significant difference in the supine position rather than the 
upright position. The possible mechanism is that a bolus transported in the supine position only depends on esophageal function, while the upright position has the help of gravity. The esophagus must work harder to transport a bread bolus in the supine position ${ }^{23}$ and some subjects failed to respond to the "physiological challenge" of solid swallows. Then failed swallows and very hypotensive peristalsis were increased in solid swallows.

The normative values are not universal and valid for different manometry systems and catheters. For example, the $2.7 \mathrm{~mm}$ thick solid-state HRM catheter provides somewhat different data from the usually used $4.2 \mathrm{~mm}$ thick catheter. ${ }^{24}$

In conclusion, specific normative values should be applied in different study conditions. Supine solid swallows are more easily accompanied by hypotensive peristalsis. Also, a synthetic evaluation of esophageal function in the supine and upright positions for liquids and solids may be more helpful in making diagnosis.

\section{References}

1. Clouse RE, Staiano A, Alrakawi A, Haroian L. Application of topographical methods to clinical esophageal manometry. Am J Gastroenterol 2000;95:2720-2730.

2. Fox MR, Bredenoord AJ. Oesophageal high-resolution manometry: moving from research into clinical practice. Gut 2008;57:405-423.

3. Salvador R, Dubecz A, Polomsky M, et al. A new era in esophageal diagnostics: the image-based paradigm of high-resolution manometry. J Am Coll Surg 2009;208:1035-1044.

4. Soudagar AS, Sayuk GS, Gyawali CP. Learners favour high resolution oesophageal manometry with better diagnostic accuracy over conventional line tracings. Gut 2012;61:798-803.

5. Fox M, Hebbard G, Janiak P, et al. High-resolution manometry predicts the success of oesophageal bolus transport and identifies clinically important abnormalities not detected by conventional manometry. Neurogastroenterol Motil 2004;16:533-542.

6. Pandolfino JE, Ghosh SK, Rice J, Clarke JO, Kwiatek MA, Kahrilas PJ. Classifying esophageal motility by pressure topography characteristics: a study of 400 patients and 75 controls. Am J Gastroenterol 2008;103:27-37.

7. Bredenoord AJ, Fox M, Kahrilas PJ, Pandolfino JE, Schwizer W, Smout AJ. Chicago classification criteria of esophageal motility disorders defined in high resolution esophageal pressure topography. Neurogastroenterol Motil 2012;24(suppl 1):57-65.

8. Pandolfino JE, Fox MR, Bredenoord AJ, Kahrilas PJ. High-resolution manometry in clinical practice: utilizing pressure topography to classify oesophageal motility abnormalities. Neurogastroenterol Motil 2009;21:796-806.

9. Park MI. Recent concept in interpreting high-resolution manometry. J Neurogastroenterol Motil 2010;16:90-93.

10. Chang FY, Lee CT, Yeh CL, Lee SD. Alteration of distal esoph- ageal motor functions on different body positions. Hepatogastroenterology 1996;43:510-514.

11. Sears VW Jr, Castell JA, Castell DO. Comparison of effects of upright versus supine body position and liquid versus solid bolus on esophageal pressures in normal humans. Dig Dis Sci 1990;35:857864.

12. Roman S, Damon H, Pellissier PE, Mion F. Does body position modify the results of oesophageal high resolution manometry? Neurogastroenterol Motil 2010;22:271-275.

13. Sweis R, Anggiansah A, Wong T, Kaufman E, Obrecht S, Fox M. Normative values and inter-observer agreement for liquid and solid bolus swallows in upright and supine positions as assessed by esophageal high-resolution manometry. Neurogastroenterol Motil 2011; 23:509, e198.

14. Xiao Y, Read A, Nicodème F, Roman S, Kahrilas PJ, Pandolfino JE. The effect of a sitting vs supine posture on normative esophageal pressure topography metrics and Chicago Classification diagnosis of esophageal motility disorders. Neurogastroenterol Motil 2012;24: e509-e516.

15. Allen ML, Mellow MH, Robinson M. Manometry during food ingestion aids in the diagnosis of diffuse esophageal spasm. Am J Gastroenterol 1992;87:568-571.

16. Bernhard A, Pohl D, Fried M, Castell DO, Tutuian R. Influence of bolus consistency and position on esophageal high-resolution manometry findings. Dig Dis Sci 2008;53:1198-1205.

17. Lee J, Anggiansah A, Anggiansah R, Young A, Wong T, Fox M. Effects of age on the gastroesophageal junction, esophageal motility, and reflux disease. Clin Gastroenterol Hepatol 2007;5:1392-1398.

18. Pandolfino JE, El-Serag HB, Zhang Q, Shah N, Ghosh SK, Kahrilas PJ. Obesity: a challenge to esophagogastric junction integrity. Gastroenterology 2006;130:639-649.

19. Vega KJ, Langford-Legg T, Jamal MM. Ethnic variation in lower oesophageal sphincter pressure and length. Aliment Pharmacol Ther 2008;28:655-659.

20. Tutuian R, Elton JP, Castell DO, Gideon RM, Castell JA, Katz PO. Effects of position on oesophageal function: studies using combined manometry and multichannel intraluminal impedance. Neurogastroenterol Motil 2003;15:63-67.

21. Howard PJ, Maher L, Pryde A, Heading RC. Systematic comparison of conventional oesophageal manometry with oesophageal motility while eating bread. Gut 1991;32:1264-1269.

22. Basseri B, Pimentel M, Shaye OA, Low K, Soffer EE, Conklin JL. Apple sauce improves detection of esophageal motor dysfunction during high-resolution manometry evaluation of dysphagia. Dig Dis Sci 2011;56:1723-1728.

23. Daum C, Sweis R, Kaufman E, et al. Failure to respond to physiologic challenge characterizes esophageal motility in erosive gastro-esophageal reflux disease. Neurogastroenterol Motil 2011;23: 517, e200.

24. Xiang X, Tu L, Zhang X, Xie X, Hou X. Influence of the catheter diameter on the investigation of the esophageal motility through solid-state high-resolution manometry. Dis Esophagus Published Online First: 5 Feb 2013. doi: 10.1111/dote.12029. 